\title{
A NATUREZA É MULHER: A NATUREZA ANTE O SUJEITO MODERNO NA PERSPECTIVA DE MARCUSE ${ }^{1}$
}

\author{
John Karley de Sousa Aquino ${ }^{2}$
}

\begin{abstract}
Resumo:
O presente artigo desenvolverá a hipótese de que a relação hostil da sociedade moderna com a natureza é influenciada e reforçada pela cultura patriarcal que entende que a natureza por ser mulher é passível de todo tipo de violência. As principais referências serão textos do filósofo Herbert Marcuse que abordam a noção de masculino e feminino, assim como o de alguns autores e autoras que trataram da questão do gênero em relação aos comportamentos socioculturais. Concluímos que a subjetividade moderna é de caráter masculino e que isso influenciou nossa relação com a natureza.
\end{abstract}

Palavras-chave: Marcuse. Natureza. Feminino. Masculino.

\section{NATURE WOMAN: NATURE OPPOSITE THE MODERN SUBJECT IN MARCUSE'S PERSPECTIVE}

\begin{abstract}
:
This paper will develop the hypothesis that the hostile relationship of modern society with nature is influenced and reinforced by the patriarchal culture that understands nature as a woman who is susceptible to all types of violence. The main reference will be texts by the philosopher Herbert Marcuse which address the notion of male and female, as well as those by some authors who have de alt with the issue of gender in relation to sociocultural behaviors. We conclude that modern subjectivity came from a masculine character on which it has influence do relationship with nature.
\end{abstract}

Keywords: Marcuse. Nature. Female. Male.

\section{Introdução}

A dominação da natureza está na raiz do projeto moderno. Apesar das discordâncias epistemológicas tanto o racionalismo cartesiano quanto o empirismo de Bacon concordam que o conhecimento se demonstraria útil caso dominasse a natureza, nos tornando "senhores" dela. A conquista e dominação da natureza é o "núcleo de toda racionalidade

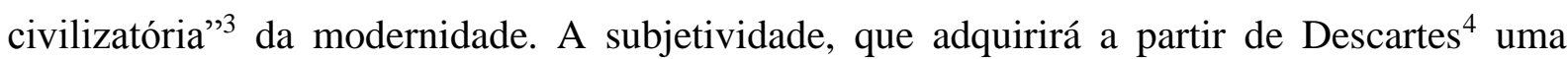

1 O presente artigo é uma adaptação da palestra de mesmo título proferida no dia 06 de agosto de 2019 no I Encontro nacional de Filosofia da técnica e educação (ENFITE/UVA) que aconteceu na Universidade Estadual Vale do Acaraú (UVA) em Sobral.

2 Professor EBTT do Instituto Federal do Ceará (IFCE)/Campus Itapipoca. Doutorando em filosofia pela Universidade Federal do Ceará (UFC), membro de pesquisa do GP-MARCUSE (UECE), GEM (UFC) e do CENTELHA (IFCE).E-mail: johnksousa@gmail.com.

3 ADORNO, HORKHEIMER, 1985, p. 60.

4 Sujeito é o Eu, "o Eu é consciência, isto é, relação consigo mesmo, subjetividade" (ABBAGNAMO, 1962, p. 368). É o modo "como que o homem designa a si mesmo, tornou-se objeto de investigação filosófica desde o momento em que a referência do homem a si mesmo, como reflexão sobre si ou consciência, se assumiu como definição do homem. O que acontece com Descartes; e foi Descartes precisamente, quem pela primeira vez colocou em termos explícitos o problema do Eu (grifo nosso)" (ABBAGNAMO, 1962, p. 368). 
centralidade fundamental na filosofia moderna, é pensada em uma relação antagônica com a realidade objetiva. As coisas existiriam para serem usadas e manipuladas por nós e como a natureza não é sujeito, mas objetividade, então ela estaria a nossa disposição para ser usada como bem entendêssemos. A natureza antes pensada como "espelho de Deus" é relegada pela racionalidade moderna a condição de matéria-prima para a indústria.

O problema que será o fio condutor deste artigo consiste em saber a partir das indicações do filósofo Herbert Marcuse se a nossa relação agressiva e predatória em relação à natureza não seria legitimada pela nossa cultura patriarcal que compreende a realidade natural como algo feminino e, portanto, passível de todo tipo de violência? Em suma, a natureza não teria sido considerada pela sociedade moderna como algo a ser dominada, explorada e violentada por ela ser histórica e culturalmente considerada mulher?

O objetivo geral é demonstrar que a relação hostil que a sociedade moderna estabeleceu com a natureza é reforçada pela nossa cultura patricêntrica que entende a natureza como uma mulher a ser dominada e explorada. Para realizar nosso objetivo geral iremos desenvolver os seguintes objetivos específicos: (1) expor as concepções hermenêuticas de Heidegger e Husserl que influenciaram Marcuse, (2) resumir a noção de subjetividade agressiva de Marcuse e (3) explicar o que Marcuse entende por características masculinas e femininas e sua relevância social.

A referência bibliográfica principal serão os ensaios de Marcuse dos anos 70 Marxismo e feminismo e Agressividade na sociedade tecnológica, onde ele aborda a questão da feminilidade em oposição aos caracteres tidos como masculino. O texto de Fromm A teoria do direito materno e sua relevância para a psicologia social (1934) será utilizado como apoio, além de outros escritos que abordam a questão do feminino e sua relação com a sociedade, como os de Angela Davis, Margaret Mead e Marija Gimbutas, autoras que pensaram a relação do gênero e seu impacto no comportamento social.

Nosso intuito não é contribuir ou discutir com as atuais teorias de gênero, afinal não temos condições nem conhecimento acumulado acerca do assunto, mas pensar a partir de Marcuse o que seria uma sociedade em que as características femininas estivessem em primeiro plano, ou seja, pensar politicamente a importância do feminino enquanto segunda natureza.

\section{A técnica e ciência moderna segundo Heidegger e Husserl}

\begin{tabular}{|l|l|l|l|l|}
\hline Govista Dialectus & Ano 9 & n. 17 & Maio - Agosto 2020 & p.124-136 \\
\hline
\end{tabular}


As concepções de Marcuse sobre a técnica e a ciência moderna são profundamente influenciadas pela hermenêutica dos seus mentores Heidegger e Husserl. Apesar da hermenêutica não ser seu principal referencial teórico, a influência juvenil permaneceu em toda sua trajetória teórica, seja de forma implícita ou de maneira explícita. As concepções de Marcuse sobre a subjetividade moderna e sua relação com a técnica e a ciência moderna são devedoras das instigantes reflexões hermenêuticas de Heidegger e Husserl. Por tal motivo nos deteremos, primeiramente, nas contribuições que esses autores trouxeram e que influenciou de modo determinante a teoria crítica de Marcuse no que se refere à técnica e à ciência moderna, enquanto problema filosófico e também prático.

O que de fato há de específico na técnica moderna? O que caracteriza de modo mais íntimo a técnica moderna é sua relação com a natureza. É uma relação hostil, de desafio, segundo Heidegger. A natureza aparece para a técnica e ciência moderna como algo a ser usada e explorada, uma matéria-prima a ser consumida. A técnica consistiria em "um desafiar (Rasfouden) que estabelece para a natureza a exigência de fornecer energia suscetível de ser extraída e armazenada enquanto tal"5. Mas a técnica pré-moderna também não explorava a natureza, retirando sua energia como fazia o moinho de vento? Para Heidegger não. A relação não era e nem podia ser hostil. O moinho de vento, por exemplo, "não retira a energia da corrente de ar para armazená-la" ${ }^{\text {. O }}$ sujeito pré-moderno convivia mais do que dominava a natureza, o que não significa que ele não quisesse, o fato é que ele não conseguia. O sujeito moderno, por sua vez conseguiu. Nós a exploramos, transformamos, armazenamos e extraímos etc, enfim, é uma relação hostil, de dominação. A natureza é dominada e explorada pela nossa técnica e ciência moderna.

Mas a essência da técnica segundo Heidegger é Gestell, uma armação ou configuração do mundo, portanto, uma determinação apriorística (no sentido hermenêutico ${ }^{7}$ ) em relação à realidade objetiva. Ela é um modo de pensar e se comportar em relação ao mundo natural e social. É por isso que Heidegger diz que a essência da técnica antecede a técnica e a ciência de facto e está na base da ciência moderna. As ciências naturais modernas são definidas por essa essência técnica, por isso constituem uma Gestell, uma configuração da realidade feita por nós que toma um aspecto do ser, o quantitativo ou o calculável, como a totalidade do ser, algo manipulável pelo sujeito através de fórmulas matemáticas. É por isso

\footnotetext{
HEIDEGGER, 2007, p. 381.

6 HEIDEGGER, 2007, p. 381.

7 “(...) qualquer ato de compreensão começa com as estruturas prévias da compreensão" (SCHIMIDT, 2013, p. 146).
}

\begin{tabular}{|l|l|l|l|l|}
\hline Q Povista Dialectus & Ano 9 & n. 17 & Maio - Agosto 2020 & p.124-136 \\
\hline
\end{tabular}


que Whitehead diz que a ciência moderna é caolha, pois só ver com um olho, e "tudo quanto que não coubesse em seu esquema era omitido, ridicularizado e descrido" ${ }^{\text {. }}$.

Para Heidegger e Husserl, assim como para Whitehead, a ciência e a técnica deixaram a muito tempo de ser meros instrumentos e tornaram-se o modo determinante de se sentir e entender o mundo, um a priori histórico como diz Marcuse. Nossa forma de lidar com a realidade, seja do ponto de vista cognitivo ou prático é técnico e mediado pela técnica. Como diz Heidegger em um curso de verão em 1941, a técnica seria o modo hoje dominante de "interpretar o mundo". Cito,

O que chamamos de técnica moderna não é somente uma ferramenta, um meio diante do qual o homem atual pode ser senhor ou escravo; previamente a tudo isso e acima das atitudes possíveis, essa técnica é um modo definido de interpretação do mundo, que não apenas determinou os meios de transporte, a distribuição de alimentos e a indústria do lazer, mas toda atitude do homem e suas possibilidades ${ }^{9}$.

Segundo Husserl os cientistas não se dão conta que sua forma de entender a realidade não é a única e nem é definitiva, mas é historicamente e culturalmente determinada. Por isso ele define a ciência moderna como ingênua, pois desconhece seus próprios pressupostos. A atividade científica não é nem neutra nem independente, mas desde o princípio determinada pelo "mundo vivido" do cientista, isto é, a sua realidade circundante. As perguntas que ele faz, os métodos e instrumentos que ele utiliza, tudo é histórica e socialmente determinado, "é o mundo circundante vital (lebensumwelt), que constantemente é pressuposto como base, como terreno da atividade, sobre o qual suas perguntas e seus métodos de pensar adquirem um sentido"10. O mundo vivido é uma espécie de círculo hermenêutico $^{11}$, um a priori que define antecipadamente como nos relacionamos com a realidade objetiva. Em síntese, a relação do sujeito com o objeto (no caso o mundo) não é imediata, mas mediada pelo nosso contexto cultural e histórico, o nosso mundo vivido. A ingenuidade da ciência e do sujeito moderno é acreditar que sua relação com o mundo é imediata e que a nossa subjetividade não interfere em nada nessa relação, "esquece-se (...) do sujeito atuante, e o cientista não se torna tema de reflexão" ${ }^{\prime 2}$.

WHITEHEAD, 2016, p. 80.

HEIDEGGER, 1989, p. 45.

10 HUSSERL, 2002, p. 61.

11 "O círculo hermenêutico da compreensão implica que um intérprete não pode fugir do efeito da história para um ponto de vista objetivo" (SCHIMIDT, 2013, p. 167).

12 HUSSERL, 2002, p. 61.

\begin{tabular}{|l|l|l|l|l|}
\hline Q Povista Dialectus & Ano 9 & n. 17 & Maio - Agosto 2020 & p.124-136 \\
\hline
\end{tabular}


Para Husserl, Kant percebeu essa ingenuidade da ciência e decidiu que era preciso antes de conhecer o mundo questionar-se se somos de fato capazes de conhecer o mundo e com isso inaugura a "metafísica da subjetividade", estabelecendo na filosofia uma "atitude reflexiva" ou "fenomenológica". Kant teria errado ao acreditar que este "Eu", sujeito que conhece o mundo objetivo, é um "sujeito puro", ou seja, eterno e imutável. Ele não teria percebido que ser sujeito é ser sujeito no mundo, em um contexto, e que essa subjetividade é histórica, pois são "seres humanos vivendo em comunidade de seu mundo circundante e de sua época histórica" ${ }^{\prime 13}$. Em síntese, o modo como o sujeito e objeto se relaciona é histórica e culturalmente variável. O sujeito transcendental kantiano não é um "eu puro", mas o europeu moderno: homem branco, burguês, heterossexual e determinado a dominar a natureza.

A reflexão de Marcuse sobre a subjetividade moderna e sua relação com a natureza parte dessas conclusões hermenêuticas e das contribuições da psicanálise freudiana. Nossa hipótese é que o sujeito moderno tem gênero definido, é "masculino" e que a sua relação com a natureza, tida historicamente no ocidente como mulher, é pautada por esse $a$ priori técnico, que entende a realidade natural como algo a ser dominada, explorada e violentada, em síntese, submetida ao desejo e vontade desse sujeito viril.

\section{A agressividade do sujeito moderno em sua relação com a natureza}

A subjetividade de cada um é definida na infância ${ }^{14}$ na relação com os pais (ou seus equivalentes simbólicos) e por fatores sociais, como a classe social, a cultura e o contexto histórico, ou seja, o sujeito é feito, não existe desde o princípio nem do ponto de vista individual nem social.

A subjetividade se constitui a base da repressão das pulsões de vida e de morte, Eros e Thanatos. Eros, ou pulsão de vida, sintetiza os instintos de autopreservação e de reprodução sexual e tem como meta preservar a promover a vida. Thanatos pretende exatamente o oposto. É a pulsão de morte e agressividade. Seu objetivo é destruir a vida, conduzindo o que é orgânico à condição de inorgânico, sendo sua expressão externa a agressividade. As duas pulsões buscam o prazer e evitam a dor. Os pais e a sociedade reprimem as pulsões do indivíduo para que ele torne-se "sociável", apto a viver em sociedade,

13 HUSSERL, 2002, p. 61.

14 FREUD, 1996, p. 159.

\begin{tabular}{|l|l|l|l|l|}
\hline Rovista Dialectus & Ano 9 & n. 17 & Maio - Agosto 2020 & p.124-136 \\
\hline
\end{tabular}


caso contrário as relações intersubjetivas seriam impossíveis. Em suma, viver em sociedade implica no "sacrifício de seus instintos"15.

A hipótese de Marcuse é que historicamente o sujeito que se constituiu foi um sujeito agressivo em relação à realidade, devido à repressão que incide sobre Eros ser maior que a sobre Thanatos e que essa agressividade sobrevém mais fortemente na constituição do sujeito moderno que é, segundo Marcuse, "um sujeito essencialmente agressivo e ofensivo,

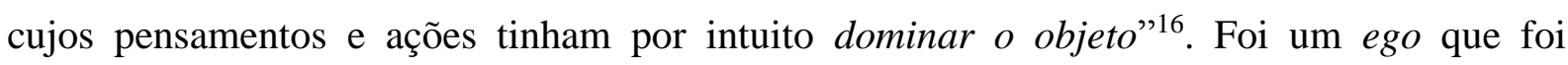
projetado para dominar o objeto, "era um sujeito contra o objeto" 17 . O primeiro objeto a ser dominado e usado pelo sujeito moderno seria a natureza.

Um dos principais esforços da obra de Marcuse é demonstrar que a relação hostil do sujeito em relação ao objeto não é a única, mas uma das possíveis relações que se tornou efetiva na modernidade e que a relação do sujeito com o objeto é determinada pelas condições históricas e sociais na qual o sujeito está inserido, isto é, o transcendental ou as categorias $a$ priori seriam variáveis sócio-historicamente. O sujeito kantiano é historicizado por Marcuse de maneira que as categorias a priori não seriam atemporais, mas radicalmente históricas, em síntese, as condições de possibilidade do conhecimento e do agir humano seriam históricas e sociais e não "puras". Segundo Andrew Feenberg nessa releitura da noção de a priori kantiano

\begin{abstract}
As condições da experiência não estão mais na mente, mas na sociedade. Em aplicações marxistas essas condições surgem de práticas associadas com o modo de produção. Em uma forma vagamente naturalizada, o conceito kantiano agora pertence ao senso comum, apesar do termo a priori ainda ser próprio da linguagem técnica dos filósofos. Mas todos nós estamos cientes de que tendemos a ver o que esperamos ver, e que essas expectativas são devido a condições psicológicas ou sociais. Dessa maneira, a idéia de pré-condições da experiência a priori é trivializada, mas também completamente familiar ${ }^{18}$.
\end{abstract}

A historicidade do sujeito determinaria o modo como os indivíduos fazem ciência,

A ciência observa, calcula e teoriza a partir de uma posição nesse universo. As estrelas que Galileu observou eram as mesmas da antiguidade clássica, mas o universo diferente de discurso e ação - em resumo, a realidade social diferente -

15 FREUD, 1974, p. 116.

16 MARCUSE, 1972, p. 107.

17 MARCUSE, 1972, p. 107.

18 FEENBERG, 2012, p. 143.

\begin{tabular}{|l|l|l|l|l|}
\hline Qevista Dialectus & Ano 9 & n. 17 & Maio - Agosto 2020 & p.124-136 \\
\hline
\end{tabular}


inaugurou a nova direção e o novo alcance da observação e as possibilidades de ordenar os dados observados ${ }^{19}$.

Em síntese, "a cabeça pensa onde o pé pisa".

A relação antagônica entre o sujeito e o objeto, que Marcuse define como pautada por uma lógica de dominação, funda uma forma a priori do sujeito de se relacionar com a realidade e determina "uma experiência e organização específicas da realidade" ${ }^{20}$. Este a priori depende do mundo vivido, no qual o sujeito está vivendo e desde o início da história "civilizada" o mundo em que o sujeito vive é um mundo fundado e mantido por relações de dominação e exploração. Exploração da classe trabalhadora e dominação da mulher. Tanto a sociedade de classes quanto o patriarcado são anteriores ao capitalismo.

A sociedade moderna não abole a divisão de classes, ela apenas altera essa relação, não abole o patriarcado, mas o reforça. Para Marcuse o sujeito moderno é o europeu burguês do século XVII e XVIII, ou seja, tem classe e cor. O que ele não percebeu, até o final dos anos 60 e início da década de 70 (mas seu colega de Instituto Erich Fromm percebeu desde os anos 30) é que esse sujeito não só tem classe, não só tem raça, como também tem gênero, é "masculino".

Nos final dos anos 60 e início dos anos 70, sobretudo em dois textos (Marxismo e feminismo e $O$ fracasso da nova esquerda?), Marcuse iniciará uma crítica do que ele define como "características masculinas" do sujeito moderno, que devem ser superadas, para que uma "nova subjetividade" se desenvolva e leve a cabo o projeto socialista.

Diante do que foi exposto levanto a seguinte hipótese, a partir de Marcuse, mas também de Fromm: não seria tal relação hostil do sujeito com a natureza reforçada pelo fato desse sujeito ser masculino e a natureza associada ao feminino? Isto é, a relação de dominação do sujeito moderno com a natureza não seria fortemente influenciada pelo que Fromm definiu como "complexo patricêntrico" ${ }^{21}$ do sujeito? Em síntese, a natureza não teria sido dominada, explorada e violentada pelo fato dela ser histórica e culturalmente considerada mulher? Consideramos que sim e desenvolveremos melhor nossa hipótese na próxima seção.

\section{Uma nova relação com a natureza em uma sociedade feminina}

19 MARCUSE, 2015, p. 164.

20 MARCUSE, 2015, p. 169.

21 "Complexo patricêntrico é uma estrutura psíquica em que as relações do indivíduo com o pai (ou seus equivalentes psicológicos) constituem as relações centrais" (FROMM, 1977, p. 124), ou seja, o nosso ego se constitui tendo como referência central a figura masculina, o homem.

\begin{tabular}{|l|c|c|c|c|}
\hline Qonista Dialectus & Ano 9 & n. 17 & Maio - Agosto 2020 & p.124-136 \\
\hline
\end{tabular}


Na conferência de 1974, Marxismo e feminismo, Marcuse desenvolve mais uma vez sua ideia de que o sujeito moderno é um sujeito agressivo em relação à realidade (e a outros sujeitos), que é um sujeito que devido a mais-repressão que incide, sobretudo, sobre Eros uma "mais-agressão é liberada"22, mas pela primeira vez associa explicitamente a subjetividade agressiva e hostil a masculinidade. Ele define esse sujeito como um sujeito em que as características masculinas são primárias, determinantes, enquanto as características femininas são secundárias, inferiorizadas.

Características masculinas? Tal hipótese pode ser mal interpretada no contexto atual e por isso precisam ser explicadas melhor. "Homem" e "mulher", masculino e feminino, na compreensão de Marcuse não são realidade naturais, mas sócio-históricas, em síntese, as características masculinas e femininas são "socialmente condicionadas" 23 e de jeito nenhum, características "naturais, biológicas" 24 . O que Marcuse está dizendo não difere muito do que disse Simone Beauvoir de que "não se nasce mulher, torna-se mulher" e de que "nenhum destino biológico, psíquico ou econômico define a forma que a mulher ou a fêmea humana assume no seio da sociedade" 25 e da teoria de gênero atual para o qual gêneros são construções sociais. Mas Marcuse defende algo que pode soar estranho. Para ele tais construções sociais são bastante sólidas e efetivas e não são desconstruídas tão facilmente. Houve "um longo processo histórico durante o qual as características sociais, mentais e mesmo fisiológicas das mulheres se desenvolveram diferentemente do, e em contraste, com a dos homens" 26 . Foi um processo milenar onde se definiram as características associadas ao homem, masculinas e as associadas às mulheres, femininas, com a qual podemos até não concordar, mas que existem, estão aí e temos que lidar com tal realidade que é patriarcal e privilegia as características masculinas em detrimento das femininas e é hostil a tudo que se associa a feminilidade ${ }^{27}$. E nessa conferência de 74 , Marcuse considera que muito dos problemas da nossa sociedade e da história humana, decorrem justamente dessa masculinidade inerente a ela que transforma meninos em homens agressivos, violentos e dominadores, enquanto às mulheres adquiriram (ou seja, não nasceram) outras características que não são valorizadas pela sociedade patriarcal.

22 MARCUSE, 2018a, p. 40.

23 MARCUSE, 2018b, p. 40.

24 MARCUSE, 2018b, p. 79.

25 BEAUVOIR, DS II, 1980. p. 9.

26 MARCUSE, 2018b, p. 78.

27 "O instinto se opõe à reflexão, como a receptividade e a gratificação são opostas à atividade e à dominação, então o princípio feminino presunçosamente (embora às vezes de maneira utópica) se contrapõe ao princípio masculino" (DAVIS, 2000, p. 149).

\begin{tabular}{|l|l|l|l|l|}
\hline Q Povista Dialectus & Ano 9 & n. 17 & Maio - Agosto 2020 & p.124-136 \\
\hline
\end{tabular}


O conceito de masculino e feminino em Marcuse deve ser entendido conforme sua definição de segunda natureza, uma noção aristotélica e hegeliana que pensa a subjetividade humana como algo socialmente construído seja através dos hábitos (Aristóteles) ou da história (Hegel). Para Aristóteles a prática constante das mesmas ações nos torna habituados a repetilas, de modo que nos tornamos resistentes a mudar velhos hábitos, pois o hábito seria algo que "muda dificilmente porque se assemelha à natureza, como diz Eveno: O hábito, meu caro, não é senão uma longa prática que acaba por fazer-se natureza (grifo no original)"28. Hegel, que é quem Marcuse mais se baseia, retoma essa concepção aristotélica de segunda natureza e a associa aos hábitos de um povo, enquanto regras de sociabilidade. Esses hábitos determinam como um povo comporta-se efetivamente de modo ético, constituindo uma espécie de moralidade imediata ${ }^{29}$. Para Marcuse "uma vez que a moralidade específica se estabelece firmemente como norma de comportamento social, não é somente projetada - também opera como norma de comportamento "orgânico" 30 , tornando-se nossa segunda natureza no sentido aristotélico e hegeliano. É dessa forma que a masculinidade e feminilidade devem ser entendidas na antropologia filosófica de Marcuse, como constructos sociais consolidados pela história e pelo hábito.

O que Marcuse está tematizando nos anos 70, Erich Fromm já havia tematizado nos anos 30 em A teoria do direito materno e sua relevância para a psicologia social (1934). Nesse ensaio, baseando-se em achados arqueológicos e defendendo a hipótese de que antes da sociedade patriarcal existiu uma sociedade matriarcal, Fromm vai associar a subjetividade e a sociedade patricêntrica à sociedade de classes.

Achados arqueológicos comprovaram que a sociedade de classes surge juntamente com o estabelecimento do patriarcado e que por isso desde o princípio a subjetividade masculina se associou a reprodução de relações de dominação e exploração, de modo que o sujeito patricêntrico e a família patriarcal onde ele é constituído "é um dos mais importantes núcleos de produção das atitudes psíquicas que operam para manter a estabilidade da sociedade de classes" 31 .

A Arqueóloga lituana Marija Gimbutas (1921-1994) em 1956 apresentou a hipótese Kurgaem que defende que na Europa antiga do período neolítico existiu uma sociedade "matrística", centralizada na figura da mulher (representada religiosamente como

28 ARISTÓTELES: 1973, 1152a, 30.

29 HEGEL, 2010, $\$ 151$.

30 MARCUSE, 1977, p. 24.

31 FROMM, 1977, p. 119.

\begin{tabular}{|l|l|l|l|l|}
\hline Revista Dialectus & Ano 9 & n. 17 & Maio - Agosto 2020 & p.124-136 \\
\hline
\end{tabular}


“A Deusa mãe") que foi invadida, dominada e substituída por culturas kurgande origem indoeuropeia "androcráticas", isto é, centrada na figura do homem, uma cultura guerreira que impôs na Europa antiga o patriarcado e criou as condições para o aparecimento da sociedade de classes antiga. A sociedade matricêntrica primitivas teria uma cultura pacífica, aceitavam comportamentos fora dos padrões heteronormativos, possuíam poucas restrições sexuais e prevalecia a igualdade econômica. Tal sociedade teria sido substituída através da força pela sociedade patriarcal que impôs na Europa Antiga uma cultura patricêntrica ${ }^{32}$.

Para o jovem Fromm (1934) e Marcuse, a sociedade patriarcal promove a constituição de subjetividades com características masculinas que seriam, segundo Fromm “dependência afetiva da autoridade, envolvendo um misto de ansiedade, amor e ódio (...), superego forte e austero, cujo princípio é que o dever tem mais importância do que a felicidade, sentimentos de culpa (...)"33. Tais características teria como resultado "manter as pessoas dóceis ante a autoridade" ${ }^{34}$. Para Marcuse se associariam a masculinidade a agressividade, severidade, culpabilidade, sadismo e dominação, as características que citamos como sendo características do sujeito moderno. Para ambos, nessa sociedade patricêntrica tudo associado à feminilidade "passou a ser considerado inferior, mais fraco, basicamente como suporte ou auxiliar do homem" 35 . Como milenarmente a natureza foi associada à mulher $^{36}$, o que podemos ver na religião primitiva da Deusa-mãe (Deusas que criam, geram a vida, mas nunca destroem, apenas constroem e pela arqueologia era a religião específica do período paleolítico e neolítico), na Gaia grega, A Jord nórdica, A Nidaba suméria etc., a civilização patriarcal se sentiu autorizada a dominar, explorar e violentar a natureza "tida como hostil, mistério inexorável, resistência a ser quebrada"37, considerada mulher. A sociedade masculina reproduziria na sua relação com a natureza uma relação patriarcal estabelecida milenarmente com as mulheres.

O sujeito moderno leva às últimas consequências a dominação social da natureza a ponto de esgotar os recursos e ameaçar a própria realidade natural. Nesse sentido nossa hipótese é que somente uma nova subjetividade em que existe uma "preponderância (...) dos instintos de vida sobre os instintos de morte, uma preponderância da energia erótica sobre as

32 GIMBUTAS, 1991.

33 FROMM, 1977, p. 120.

34 FROMM, 1977, p. 120.

35 MARCUSE, 2018b, p. 82.

36 "um tema ideológico recorrente proclama que as mulheres estão firmemente ancoradas no domínio da natureza" (DAVIS, 2000, p. 149), isto é, são mais associadas e dominadas pela natureza que os homens.

37 "Nature is posited as hostility, mysterious inexorable, a resistance to be broken" (DAVIS, 2000, p. 149).

\begin{tabular}{|c|c|c|c|c|}
\hline Revite (2)idlectus & Ano 9 & n. 17 & Maio - Agosto 2020 & p.124-136 \\
\hline
\end{tabular}


pulsões destrutivas" ${ }^{\prime 3}$, que estabeleceria uma nova relação com os outros e com a natureza, redefinindo a relação humana com a natureza, poderia impedir a contínua catástrofe ambiental promovida pela sociedade capitalista. Um sujeito com "características femininas"39. O socialismo enquanto uma proposta de sociedade sem exploração e dominação, diz Marcuse, deveria promover "a libertação e ascensão das características femininas na escala social"40, gerando um novo princípio de realidade, contrário ao estabelecido, que é masculino. Tal hipótese é desenvolvida pela orientanda de Marcuse, a filósofa Ângela Davis, no seu fenomenal ensaio Women and capitalisme parcialmente em Mulheres, Raça e classe, onde a autora entende o machismo e violência contra a mulher com uma "muleta essencial para o capitalismo" 41 .

Daí a importância do feminismo para o socialismo na concepção tanto de Marcuse quanto de Ângela Davis. Ele promoveria a superação da subjetividade patricêntrica tornando as características masculinas secundárias e as femininas voltariam a serem as principais ${ }^{42}$. Para ele "no próprio movimento está contido a imagem não apenas de novas instituições, mas também de mudança de consciência, de uma mudança nas necessidades instintivas de homens e mulheres, libertos das exigências de dominação e exploração"43. Ao invés de dominar a natureza uma sociedade feminina e socialista passaria a cuidar e preservar a natureza, como acontece na cultura matricêntrica Arapexe estudada pela antropóloga Mararet Mead e citada por Marcuse em Eros e civilização como exemplo de uma nova relação com a natureza, diferente da relação hostil da sociedade moderna,

Para os arapexes, o mundo é uma plantação que deve ser lavrada, não por si mesmo, não no orgulho e jactância, não para a cumulação e a usura, mas para os inhames e os cachorros, e os porcos, e, acima de tudo para que as crianças possam crescer. Desta atitude geral derivam muitos dos outros traços arapesh, a ausência de conflito entre velhos e moços, a ausência de ciúme ou inveja, a ênfase na cooperação. (...). É possível dizer que a concepção dominante quanto a homens e mulheres é a de encarar os homens exatamente como nós visualizamos as mulheres, isto é, gentil e cuidadosamente maternais em seus intuitos (grifo nosso) ${ }^{44}$.

38 MARCUSE, 2018a, p. 40.

39 MARCUSE, 2018b, p, 86-87.

40 MARCUSE, 2018b, p. 80.

41 DAVIS, 2016, p. 203.

42 Para Ângela Davis o feminismo seria inerentemente anticapitalista e "as trabalhadoras, portanto, tem um interesse vital e particular na luta pelo socialismo" (DAVIS, 2016, p. 244).

43 MARCUSE, 2018b, p. 80.

44 MEAD, 1987, p.142.

\begin{tabular}{|l|l|l|l|l|}
\hline Qovista Dialectus & Ano 9 & n. 17 & Maio - Agosto 2020 & p.124-136 \\
\hline
\end{tabular}


A partir dessa citação de Margaret Mead, Marcuse vai dizer o seguinte, e concluo com esta citação, diz ele: "primacial, nesta descrição, parece ser a fundamentalmente diferente experiência do mundo; a natureza é considerada, não um objeto de dominação e exploração, mas um 'jardim', que pode crescer enquanto faz que os seres humanos se desenvolvam"45.

\section{Referências}

ABBAGNAMO, Nicola. Dicionário de filosofia. Tradução de Alfredo Bosi. $2^{\circ}$ edição. São Paulo: Mestre Jou, 1962.

ADORNO, Theodor. HORKHEIMER, Max. Dialética do esclarecimento: fragmentos filosóficos. Tradução de Guido Antônio Almeida. Rio de Janeiro: Zahar edições, 1985.

ARISTÓTELES. Ética a Nicômaco. Tradução de Leonel Vallandro e Gerd Bornheim. São Paulo: Abril Cultural, 1973.

BEAUVOIR, Simone de. O Segundo Sexo, volume II. Tradução Sérgio Milliet. Rio de Janeiro: Nova Fronteira, 1980.

DAVIS, Ângela. Mulheres, raça e classe. Tradução Heci Regina Candiani. São Paulo: Boitempo, 2016.

Women and capitalism: dialetcs of oppression and liberation. In: The Black feminist reader. Edited by Joy James and T. Denean Sharpley-Whiting. New Jersey: Blackwell Publisher, 2000.

FEENBERG, Andrew. Fenomenologia de Marcuse: lendo o capítulo seis de O Homem unidimensional. Tradução de Vanessa di Lego. In: CONGRESSO INTERNACIONAL FANTASIA E CRÍTICA, 1, 2012, Belo Horizonte. Caderno de textos. Belo Horizonte: ABRE, 2012, p.140-152.

FREUD, Sigmund. Esboço de psicanálise (1938). In: Obras psicológicas completas de Sigmund Freud Volume XXIII. Tradução de Jayme Salomão. Rio de Janeiro: Imago, 1996.

Mal-estar na civilização (1930). In: Obras psicológicas completas de Sigmund Freud Volume XXI. Tradução de José Octávio de Aguiar Abreu. Rio de Janeiro: Imago, 1974.

FROMM, Erich. A teoria do direito materno e sua relevância para a psicologia social (1934). In: A crise da psicanálise: Freud, Marx e a psicologia social. Tradução de Álvaro Cabral. $2^{\circ}$ edição. Zahar editores: Rio de Janeiro, 1977.

GIMBUTAS, Marija. The civilization of the Goddess. San Francisco: Harper, 1991.

45 MARCUSE, 1972, p. 188.

\begin{tabular}{|c|c|c|c|c|}
\hline Revista Q Dialectus & Ano 9 & n. 17 & Maio - Agosto 2020 & p.124-136 \\
\hline
\end{tabular}


HEIDEGGER, Martin. A Questão da técnica. Tradução de Marco Aurélio Werle. In: Revista Scientiæzudia, São Paulo, v. 5, n. 3, 2007, p. 375-98.

Conceptos fundamentales: curso del semestre de verano, Friburgo, 1941. Introdudccion, traducuión y noas de Manuel E. Vázquez Gárcia. Madrid: Alianza editorial, 1989.

HEGEL, G.W.F. Linhas fundamentais da Filosofia do Direito. Tradução de Paulo Menezes et al. 2. ed. São Leopoldo, Rio Grande do Sul: Editora Unisinos, 2010.

HUSSERL, Edmund. A crise da humanidade europeia e a filosofia. Introdução e tradução de Urbano Zilles. $2^{\circ}$ Edição. Porto Alegre: EDIPUCRS, 2002.

MARCUSE, Herbert. Eros e Civilização: Uma interpretação filosófica do pensamento de Freud. Tradução de Álvaro Cabral. Rio de Janeiro: Zahar, 1972.

O Homem Unidimensional: Estudos da Ideologia da Sociedade Industrial avançada. Tradução de Robespierre Oliveira, Deborah Christina Antunes e Rafael Cordeiro Silva. São Paulo: EDIPRO, 2015.

Agressividade em sociedades industriais avançadas. Tradução de Inara Luisa Marin e Ricardo Crissiúma. In: Dossiê Herbert Marcuse, Parte 2 (Dissonância: Revista de Teoria Crítica, v. 2, n. 1. 2), 2018a, p. 20-41.

Marxismo e feminismo. Tradução de Mariana Teixeira. Dossiê Herbert Marcuse, Parte 2 (Dissonância: Revista de Teoria Crítica, v. 2, n. 1.2), 2018b, p. 77-90.

Bertrand, 1977.

Um ensaio para a libertação. Tradução de Maria Ondina Braga. Lisboa: Livraria

MEAD, Margaret. Sexo e temperamento em três sociedades primitivas. São Paulo: Perspectiva, 1987.

SCHMIDT, Lawrence k. Hermenêutica. Tradução de Fábio Ribeiro. $2^{\circ}$ Edição. Petrópolis: Vozes, 2013.

WHITEHEAD, Alfred North. A ciência e o mundo moderno. Tradução de Hermann Herbert Watzlawick. São Paulo: Paulus, 2006.

\begin{tabular}{|l|l|l|l|l|}
\hline Q Povista Dialectus & Ano 9 & n. 17 & Maio - Agosto 2020 & p.124-136 \\
\hline
\end{tabular}

